\title{
A retrospective review of birth outcomes at the Mother and Child Health Hospital in Lao People's Democratic Republic, 2004-2013
}

\author{
Sonja J. Olsen ${ }^{1 *}$, Phommady Vetsaphong ${ }^{2}$, Phouvanh Vonglokham³ ${ }^{3}$ Sara Mirza', Viengphone Khanthamaly ${ }^{4}$, \\ Touy Chanthalangsy ${ }^{2}$, Seth Chittanavanh², Bounkong Syhavong ${ }^{3}$, Ann Moen', Joseph Bresee', \\ Andrew Corwin ${ }^{4,5}$ and Anonh Xeuatvongsa ${ }^{2}$
}

\begin{abstract}
Background: The Lao People's Democratic Republic (Lao PDR) is a lower-middle income country making steady progress improving maternal and child health outcomes. We sought to ascertain if there have been improvements in three specific birth outcomes (low birth weight, preterm birth and small for gestational age) over the last decade.

Methods: We retrospectively reviewed birth records between 2004 and 2013 at the Mother and Child Health $(\mathrm{MCH})$ hospital in Vientiane. We defined preterm birth as gestation $<37$ weeks and low birth weight as $<2,500 \mathrm{~g}$. We calculated small for gestational age (SGA). We describe birth outcomes over time and compare proportions using Chi square.

Results: Between 2004 and 2013, the annual average number of newborns delivered each year was 4,322 and the frequency of low birth weight ranged from 9.5 to 12\%, preterm births from 6.3 to 10\%, and infants born SGA from 25 to 35\%. There were no improvements in these frequencies over time. Women $<18$ years at delivery had a statistically significantly higher frequency of babies born with a low birth weight $(15.3 \mathrm{vs} .10 .8 \%, p<0.02)$ or preterm $(16.4$ vs. $7.8 \%, p<0.01)$ than those aged $>18$. There was no difference in the frequency of babies born SGA by age ( $26.8 \%$ in women $<18$ years vs. $29.7 \%$ in women $>18$ years, $p=0.30)$.
\end{abstract}

Conclusions: At the largest maternal and child hospital in Lao PDR, we found a high frequency of poor birth outcomes with no improvements over the last decade.

Keywords: Pregnancy outcome, Low birth weight, Preterm birth, Small for gestational age, Lao PDR

\section{Background}

Improving maternal and child health are priorities for the United Nation's Millennium Development Goals (MDG), and the World Health Organization (WHO) recommends various measures, including antenatal care, delivery in health facilities with skilled attendants, malaria chemoprophylaxis and tetanus toxoid vaccine during pregnancy, and childhood vaccination to achieve targets in key health indicators. The Lao People's Democratic Republic (Lao PDR) is a lower-middle income country in Southeast Asia that has made numerous

\footnotetext{
*Correspondence: sco2@cdc.gov

1 Influenza Division, Centers for Disease Control and Prevention, 1600 Clifton

Road, Atlanta, GA 30329, USA

Full list of author information is available at the end of the article
}

investments in child and maternal health over the last decade that have yielded substantial gains in key health indicators [1]. Maternal mortality rates declined from 796 deaths per 100,000 live births in 1995 to 357 in 2009 [2]. Mortality among children $<5$ years declined from 170 per 1,000 live births in 1993 to 79 in 2011 [2]. Although infant mortality rates fell during this time period from 114 to 68 per 1,000 live births, rates still exceed the defined target of 45 [2]. Since 2002, with substantial investment by Gavi, a global Vaccine Alliance of public and private partners to improve access to vaccines in less wealthy countries, Lao PDR's national immunization program has expanded coverage of childhood vaccines; vaccine coverage for DTP3 increased 
from $53 \%$ in 2002 to $87 \%$ in 2013 and influenza vaccine was introduced in pregnant women in 2012 [3-5].

While these improvements are significant and bring Lao PDR closer to reaching MDG targets, Lao PDR still has one of the highest $<5$ mortality in the region, and infant and maternal mortality rates remain among the highest in the region. Furthermore, there is no information on whether there have been improvements in birth outcomes such as the proportion of infants born low birth weight, preterm or small for gestational age. To ascertain if there were improvements in birth outcomes over time we reviewed historical data from the largest maternal hospital in Lao PDR between 2004 and 2013. Reviewing these data may help us better understand birth outcomes patterns in the context of a country going through substantial economic development striving to reach their MDG goals.

\section{Methods}

\section{Study design and population}

The Mother and Child Health (MCH) hospital is a 70bed referral hospital located in Vientiane, Lao PDR. There are five large delivery hospitals in Vientiane and approximately one third of all hospital deliveries are in $\mathrm{MCH}$ [6]. We conducted a retrospective cross sectional review of hospital records of live births delivered at MCH hospital between 2004 and 2013. Routine hospital practice was to record all deliveries into a logbook with one line for each infant; each entry had age of the mother, gravida, date of delivery, sex of the baby, gestational age and birth weight of the infant. We abstracted data only on live births; stillbirths were excluded. Some log books were missing including all from the year 2007 . For births occurring in years 2004-2010, we entered all variables into a database; however, upon analysis we recognized that date of birth accuracy was limited to year only. In order to look at monthly birth patterns we then entered birth data for years 2011-2013. During this time period, we recorded only singleton births and captured date of delivery, sex of the baby, gestational age and birth weight of the infant. Using data from the hospital statistical office, we also recorded the total number of newborns delivered at MCH hospital in 2004-2011.

\section{Data analysis}

Data were entered into Excel (Microsoft Office 2010) and Access (Microsoft Office 2010) and imported into SPSS (IBM SPSS Statistics, version. 21) for analysis. In 196 (1.4\%) newborn records, gestational age was recorded as a two-week range; we selected the earlier week. We defined preterm birth as gestation $<37$ weeks and low birth weight as $<2,500 \mathrm{~g}$. We calculated small for gestational age (SGA) and large for gestation age (LGA) using the Kramer method [7]. SGA was defined as a live birth with a birth weight less than the $10^{\text {th }}$ percentile of birth weights of the same sex and same gestational age in weeks, and is expressed as a percentage of live births with gestational ages from 22 to 43 weeks. LGA was defined as a live birth with a birth weight more than the $90^{\text {th }}$ percentile of birth weights of the same sex and the same gestational, expressed as a percentage of live births with gestational ages from 22 to 43 weeks. For each individual newborn record in 2004-2010, there was no indication on whether it was a singleton or part of a multiple birth so all births were assumed to be singletons for the calculation of SGA and LGA. We used three month moving averages to smooth the curves for the proportion of birth outcomes small for gestational age, low birth weight and preterm. To compare proportions we used Chi-square and for multiple samples we used the Mantel-Haenszel test of linear association; to compare continuous variables we used the MannWhitney test for two independent samples and the Kruskal-Wallis test for $\mathrm{k}$ independent samples. A $p<0.05$ was considered significant.

\section{Results}

Between 2004 and 2013, the total number of recorded deliveries at MCH Hospital was 38,906 (Fig. 1). Excluding still births, there were 38,798 live births. Individual records on live births were available on 22,560 , or $58 \%$ of all live births reported; these records were abstracted and entered into a database. The annual average number of live births at $\mathrm{MCH}$ Hospital was 4,311 and ranged

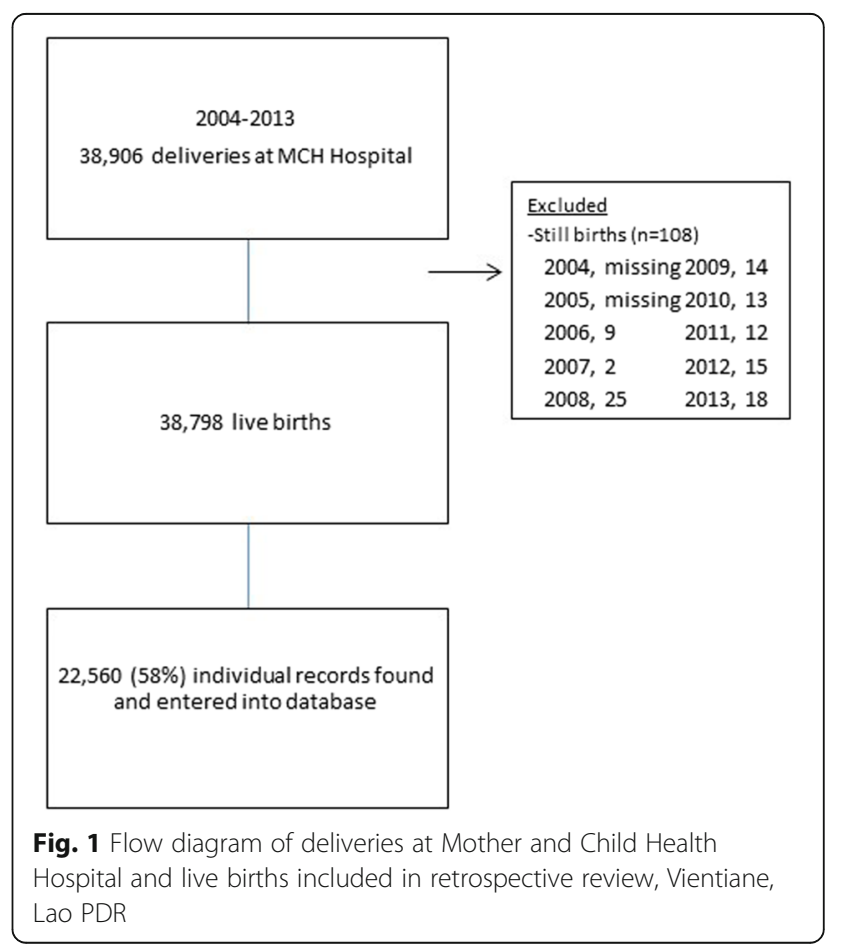


from 3,951 in 2006 to 4,898 in 2012 (Table 1). The number of births in the dataset each year ranged from 874 in 2008 to 4,263 in 2011. In all live births for which we found data, there was $>90 \%$ completeness for each variable (data not shown).

Maternal information was available in years 2004 through 2010 (Table 1). The annual mean age of mothers delivering was 26 years for all years except 2006 , when it was 25 years. Of the 13,051 women with a known age, $275(2.1 \%)$ were $<18$ years old. The annual mean number of lifetime pregnancies per woman was two, and the annual mean age at first pregnancy was 23 years for all years except 2006 when it was 24 .

Data on infants were available for all years 2004-2013 (Table 1). The annual mean birth weight was $3,014 \mathrm{~g}$ with a statistically significant difference between years $(p<0.001)$, but birth weight was $40 \mathrm{~g}$ more in the years that only included singleton births (3043 g [SD 469] in 2011-2013 vs. $3003 \mathrm{~g}$ [SD 492] in 2004-2010, $p<0.001$ ). The frequency of low birth weight $(<2,500 \mathrm{~g})$ ranged from $9.5 \%$ in 2013 to $12 \%$ in 2005 and 2009; there was no linear association with delivery year $(p=0.08)$. The annual mean gestational age was 38.8 weeks, and the frequency of preterm births ranged from $6.3 \%$ in 2004 to $10 \%$ in 2012; the linear association with delivery year was statistically significant $(p=0.002)$. The proportion of infants born SGA ranged from 25\% in 2009, 2012 and 2013 to $35 \%$ in 2005 and 2006; the linear association with delivery year was statistically significant $(p<0.001)$.

In years 2004 through 2010, for which we had maternal age at delivery, women $<18$ years old had a statistically significantly higher frequency of babies born with a low birth weight $(15.3$ vs. $10.8 \%, p<0.02)$ or preterm $(16.4$ vs. $7.8 \%, p<0.01)$ than those aged $\geq 18$ old. There was no difference in the frequency of babies born small for gestational age by age $(26.8 \%$ in women $<18$ years vs. $29.7 \%$ in women $\geq 18$ years, $p=0.30$ ). In years 2011-2013, we had monthly data on birth outcomes and observed an annual increase in the number of births in September through November in 2011 and 2012 but not in 2013 (Fig. 2). There was little variation in the monthly proportion of births born small for gestational age, preterm or low birth weight (Fig. 3).

\section{Discussion}

At the largest maternal and child hospital in Lao PDR, we found a high frequency of poor birth outcomes with no improvement over the last decade and increases in the proportions of infants born preterm and SGA. In 2013, a quarter of infants were born small for gestational age, 9.5\% low birth weight and $8.1 \%$ preterm.

Although many factors can affect birth outcomes, during this time there was substantial economic development in Lao PDR. Between 2004 and 2013, the gross national income (GNI) per capita increased from $\$ 390$ to $\$ 1,490$, and Lao PDR is now considered a lowermiddle income country [1]. It remains just barely eligible for Gavi funds $(\mathrm{GNI} \leq \$ 1580)$. Despite these substantial economic improvements, we did not observe any improvement in birth outcomes over this time period in this population. There may be several explanations. First, urban migration has increased over time, bringing women in to Vientiane Capital from rural areas [8]. If general health status and prenatal care were worse in rural areas as indicated by a recent health survey [9] this population transition may temporarily keep some health indicators low in Vientiane. Alternatively, economic improvement may not have translated into better health outcomes. There have been some improvements in maternal and child health outcomes during this time period. For example, between 2004 and 2013, infant mortality decreased from 73 to 54 per 1,000 live births and under five morality decreased from 101 to 71 per 1,000 live births [1]. However, other health outcomes, such as the prevalence of stunting (44\%) and underweight $(27 \%)$ in children $<5$ years old remain exceptionally high [9]. Maternal nutrition is an important factor in birth outcomes, and the World Food Program (WFP) began in Laos in 2000. However, the targeted efforts of WFP in the very north and very south of the country may mean that the effects are not realized in the capital city [10].

Many factors, including maternal insults during pregnancy, contribute to poor birth outcomes such as infants being born small for gestational age. Infections, including influenza, in pregnant women are associated with higher risks of severe outcomes, [11] and maternal vaccination has been demonstrated to reduce the risk of infection in an infant born to a vaccinated mother during the first 6 months of life, an age at which the child is at very high risk of severe influenza disease [12-14]. Furthermore, recent studies have demonstrated that the vaccine may also play a role in birth outcomes, such as reducing the chance that a baby is born small for gestational age [11, 15]. In 2012, Lao PDR began targeting pregnant women, specifically at $\mathrm{MCH}$ hospital, for influenza vaccination [16].

These data have several limitations. First, data were abstracted from hard-copy logbooks, some of which had gone missing over the years. However, missing logbooks were unlikely to be drastically different from those we analyzed. Second, for all but the three most recent years of data, we lacked individual-level data on whether each newborn was a singleton or part of a multiple birth. Newborns that are part of multiple births are smaller and weigh less so inclusion in the calculation of SGA may have exaggerated the number of SGA infants. It 
Table 1 Maternal characteristics and birth measures in the Maternal and Child Hospital, Lao PDR by year, 2004-2013

\begin{tabular}{|c|c|c|c|c|c|c|c|c|c|c|c|}
\hline Year & $\begin{array}{l}\text { Total no. live } \\
\text { births at MCH } \\
\text { hospital }\end{array}$ & $\begin{array}{l}\text { No. (\%) of } \\
\text { live births } \\
\text { in dataset }\end{array}$ & $\begin{array}{l}\text { Mean age of } \\
\text { mother (standard } \\
\text { deviation) }\end{array}$ & $\begin{array}{l}\text { Mean no. pregnancies } \\
\text { (standard deviation) }\end{array}$ & $\begin{array}{l}\text { Mean age in years } \\
\text { at first pregnancy } \\
\text { (standard deviation) }\end{array}$ & $\begin{array}{l}\text { Mean birth weight in } \mathrm{g} \\
\text { (standard deviation) }\end{array}$ & $\%<2,500 \mathrm{~g}$ & $\begin{array}{l}\text { Mean gestational } \\
\text { age in weeks } \\
\text { (standard deviation) }\end{array}$ & $\%<37$ weeks & $\%$ SGA & $\%$ LGA \\
\hline 2004 & missing & 2027 & $26(5.3)$ & $2(1.1)$ & $23(4.1)$ & 3019 (486) & $9.7 \%$ & $39(2.2)$ & $6.3 \%$ & $29 \%$ & $2.4 \%$ \\
\hline 2005 & 4183 & $1087(26)$ & $26(5.2)$ & $2(1.1)$ & $23(4.2)$ & $2950(483)$ & $12 \%$ & $39(2.2)$ & $9.8 \%$ & $35 \%$ & $4.6 \%$ \\
\hline 2006 & 3951 & $2075(52)$ & $25(5.3)$ & $2(1.0)$ & $24(4.9)$ & $3000(466)$ & $11 \%$ & $39(1.8)$ & $6.0 \%$ & $35 \%$ & $3.5 \%$ \\
\hline 2007 & 4255 & missing & & & & & & & & & \\
\hline 2008 & 4203 & $874(21)$ & $26(5.6)$ & $2(1.0)$ & $23(4.4)$ & 3005 (492) & $11 \%$ & $39(2.2)$ & $9.6 \%$ & $27 \%$ & $3.4 \%$ \\
\hline 2009 & 3994 & $2573(64)$ & $26(5.2)$ & $2(1.1)$ & $23(4.0)$ & 3007 (526) & $12 \%$ & $38(2.1)$ & $9.6 \%$ & $25 \%$ & $2.1 \%$ \\
\hline 2010 & 4317 & $1521(35)$ & $26(5.5)$ & 2 (1.6) & $23(4.7)$ & 3015 (478) & $11 \%$ & $39(1.9)$ & $8.4 \%$ & $31 \%$ & $3.6 \%$ \\
\hline 2011 & 4277 & 4263 (99) & NA & NA & NA & 3051 (455) & $9.6 \%$ & $39(1.7)$ & $7.1 \%$ & $26 \%$ & $2.6 \%$ \\
\hline 2012 & 4898 & $4228(86)$ & NA & NA & NA & 3029 (496) & $10.7 \%$ & $38(2.0)$ & $10 \%$ & $25 \%$ & $3.8 \%$ \\
\hline 2013 & 4720 & 3912 (83) & NA & NA & NA & 3049 (454) & $9.5 \%$ & $39(1.9)$ & $8.1 \%$ & $25 \%$ & $3.5 \%$ \\
\hline
\end{tabular}




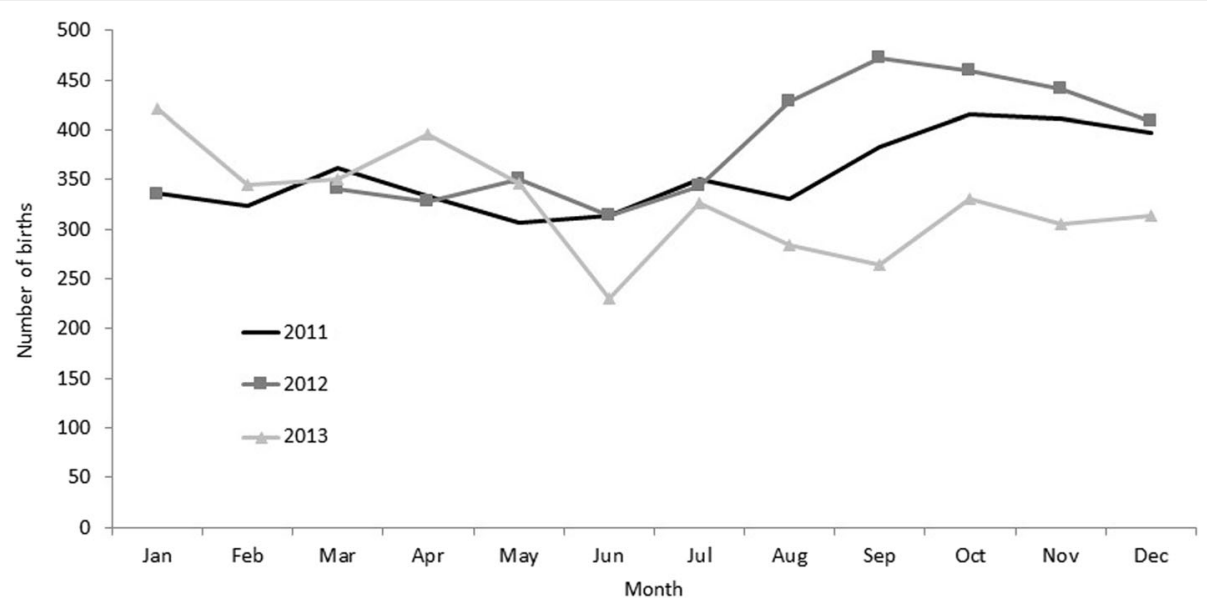

Fig. 2 Number of live births by month and year at the Mother and Child Health Hospital, Vientiane, Lao PDR, 2011-2013

may be that our population reference for calculating small for gestational age is not appropriate for Asian populations and overestimates the proportion of infants born small for gestational age. Nevertheless, with the consistent application of the methodology each year, any oberserved change was likely real. Finally, the hospital from which data were reviewed is the largest maternity hospital in Lao PDR located in Vientiane, a major urban city. It is likely that the women using this hospital may have better access to care than those from rural Lao PDR, and therefore the results may not be generalizable to rural Laos. Despite these limitations, the findings are consistent with data from other Southeast Asian nations, suggesting that our data may be fairly representative $[17,18]$.

In Lao PDR, prenatal health care, proper maternal health and nutrition and maternal education have all been demonstrated to be important factors to improve outcomes of infants [18]. Other factors, such as vaccinations, to prevent infections during pregnancy may also prove important. Our findings highlight the high burden of poor birth outcomes and the critical need for interventions.

\section{Conclusions}

An analysis of 10-years of data on live births from the largest maternal and child hospital in Lao PDR found a consistent, high frequency of poor birth outcomes. Furthermore, we found increases in the proportions of infants born preterm and SGA. These results highlight the critical need for evidence-based interventions such as prenatal health care, proper maternal health and nutrition and maternal education.

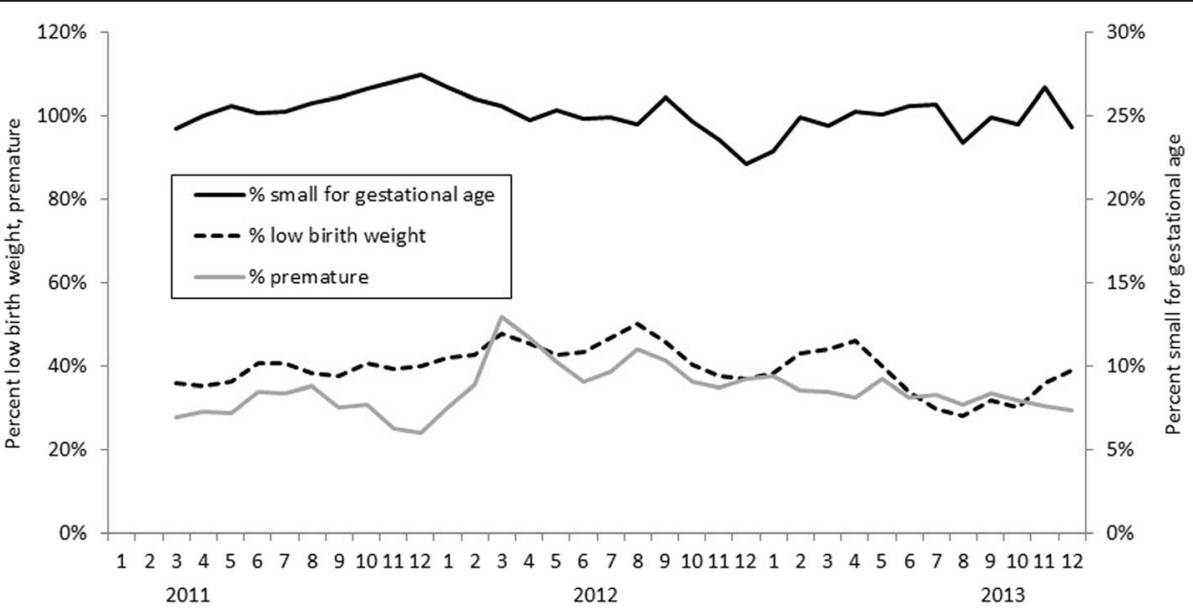

Fig. 3 Live births at the Mother and Child Health Hospital that were a) percent small for gestational age, and b) by percent preterm and percent low birth weight Vientiane, Lao PDR, by month and year 2004-2011 (Note: data were missing for February 2012) 


\section{Abbreviations}

GNI: gross national income; Lao PDR: Lao People's Democratic Republic; LGA: Large for gestation age; MCH: Mother and Child Health; MDG: Millennium Development Goals; MoH: Ministry of Health; SGA: Small for gestational age; WFP: World Food Program; WHO: World Health Organization

\section{Acknowledgements}

The authors have no one to acknowledge.

\section{Funding}

This project was funded by the Influenza Division, Centers for Disease Control and Prevention through a contract with the MCH Hospital in Vientiane, Lao PDR and by the government of Lao PDR. The funders had no role in study design, data collection and analysis, decision to publish, or preparation of the manuscript.

\section{Availability of data and materials}

The datasets generated and analyzed during the current study are available from the corresponding author on reasonable request.

\section{Authors' contributions}

All authors read and approved the final manuscript. SJO conceived and designed the evaluation, analyzed the data, wrote the paper. PV(1) conceived and designed the evaluation, collected the data, contributed to the writing of the paper. PV(2) collected the data, contributed to the analysis of the data, contributed to the writing of the paper. SM contributed to the analysis of the data, contributed to the writing of the paper. VK collected the data, contributed to the analysis of the data, contributed to the writing of the paper. TC conceived and designed the evaluation, secured permissions authorizing access to data for historical review, contributed to the writing of the paper. SC conceived and designed the evaluation, secured permissions authorizing access to data for historical review, contributed to the writing of the paper. BS conceived and designed the evaluation, contributed to the analysis of the data, contributed to the writing of the paper. AM conceived and designed the evaluation, contributed to the analysis of the data, contributed to the writing of the paper. JB conceived and designed the evaluation, contributed to the analysis of the data, contributed to the writing of the paper. AC conceived and designed the evaluation, contributed to the analysis of the data, contributed to the writing of the paper. AX conceived and designed the evaluation, contributed to the analysis of the data, contributed to the writing of the paper.

\section{Competing interests}

The authors declare that they have no competing interests.

\section{Consent for publication}

Not applicable.

\section{Ethics approval and consent to participate}

The Ministry of Health $(\mathrm{MoH})$ Institutional Ethics Review Board was not involved since the Department of Hygiene and Health Promotion, Maternal and Child Health Center, $\mathrm{MoH}$, deemed that this activity did not meet study criteria; retrospectively collected data were obtained from hospital delivery logbooks, with data entry excluding unique identifying information and presented in the aggregate. Data were de-identified prior to access by the authors. Since the purpose of collecting detailed information for aggregate analysis was carried out as part of routine neonatal (post-delivery) clinical procedure, written informed consent was not obtained from new mothers. Only one author (PV) had contact with the mothers as a treating physician providing routine clinical care at the time of the hospital visit; no authors had contact with mothers at the time of the record review.

\section{Disclaimer}

The findings and conclusions in this report are those of the authors and do not necessarily represent the views of the Centers for Disease Control and Prevention.

\section{Author details}

'Influenza Division, Centers for Disease Control and Prevention, 1600 Clifton Road, Atlanta, GA 30329, USA. ${ }^{2}$ Mother and Child Health Hospital, Vientiane,
Lao PDR. ${ }^{3}$ Ministry of Health, Vientiane, Lao PDR. ${ }^{4}$ Influenza Program, CDC, Vientiane, Lao PDR. ${ }^{5}$ The QED Group, American Embassy, Vientiane, Lao PDR.

\section{Received: 14 August 2015 Accepted: 16 November 2016} Published online: 28 November 2016

\section{References}

1. Lao PDR [http://databank.worldbank.org/data/reports.aspx?source= millennium-development-goals]. Accessed 18 Nov 2016.

2. MDGs Progress Report for the Lao PDR 2013. [http://www.la.undp.org/ content/lao_pdr/en/home/library/mdg/mdgs-progress-report-lao-pdr-2013/ ]. Accessed 18 Nov 2016

3. Partnership for Influenza Vaccine Introduction [http://pivipartners.org/] Accessed 18 Nov 2016.

4. Gavi disbursements to countries by type of support and year (2000December 31, 2014) [http://www.gavi.org/results/disbursements/]. Accessed 18 Nov 2016.

5. The Lao People's Democratic Republic [http://www.gavi.org/country/laopdr/]. Accessed 18 Nov 2016.

6. Hoehn T, Lukacs Z, Stehn M, Mayatepek E, Philavanh K, Bounnack S. Establishment of the first newborn screening program in the People's Democratic Republic of Laos. J Trop Pediatr. 2013:59(2):95-9.

7. Kramer MS, Platt RW, Wen SW, Joseph KS, Allen A, Abrahamowicz M, Blondel B, Breart G, Fetal/Infant Health Study Group of the Canadian Perinatal Surveillance S. A new and improved population-based Canadian reference for birth weight for gestational age. Pediatrics. 2001:108(2):E35.

8. Phouxay K, Tollefsen A. Rural-urban migration, economic transition, and status of female industrial workers in Lao PDR. Popul Space Place. 2011:17(5):421-34

9. UN. Lao social indicator survey, 2011-12. Vientiane: Ministry of Health and Lao Statistics Bureau; 2012

10. WFP. Lao People's Democratic Republic: A Mid-Term Evaluation of WFP's Country Programme 2012-2015. In.; 2014. http://documents.wfp.org/stellent/ groups/public/documents/reports/wfp267205.pdf. Accessed 18 Nov 2016.

11. McNeil SA, Dodds LA, Fell DB, Allen VM, Halperin BA, Steinhoff MC, MacDonald NE. Effect of respiratory hospitalization during pregnancy on infant outcomes. Am J Obstet Gynecol. 2011:204(6 Suppl 1):S54-7.

12. Eick AA, Uyeki TM, Klimov A, Hall H, Reid R, Santosham M, O'Brien KL. Maternal influenza vaccination and effect on influenza virus infection in young infants. Arch Pediatr Adolesc Med. 2011;165(2):104-11.

13. Madhi SA, Cutland CL, Kuwanda L, Weinberg A, Hugo A, Jones S, Adrian PV, van Niekerk N, Treurnicht F, Ortiz JR, et al. Influenza vaccination of pregnant women and protection of their infants. N Engl J Med. 2014;371(10):918-31.

14. Zaman K, Roy E, Arifeen SE, Rahman M, Raqib R, Wilson E, Omer SB, Shahid NS, Breiman RF, Steinhoff MC. Effectiveness of maternal influenza immunization in mothers and infants. N Engl J Med. 2008;359(15):1555-64.

15. Omer SB, Goodman D, Steinhoff MC, Rochat R, Klugman KP, Stoll BJ, Ramakrishnan U. Maternal influenza immunization and reduced likelihood of prematurity and small for gestational age births: a retrospective cohort study. PLoS Med. 2011:8(5):e1000441.

16. Phengxay M, Mirza SA, Reyburn R, Xeuatvongsa A, Winter C, Lewis H, Olsen SJ, Tsuyuoka R, Khanthamaly V, Palomeque FS, et al. Introducing seasonal influenza vaccine in low-income countries: an adverse events following immunization survey in the Lao People's Democratic Republic. Influenza Other Respi Viruses. 2015:9(2):94-8.

17. Lee AC, Katz J, Blencowe H, Cousens S, Kozuki N, Vogel JP, Adair L, Baqui AH, Bhutta ZA, Caulfield LE, et al. National and regional estimates of term and preterm babies born small for gestational age in 138 low-income and middle-income countries in 2010. Lancet Glob Health. 2013:1:e26-36.

18. Viengsakhone L, Yoshida Y, Harun-Or-Rashid M, Sakamoto J. Factors affecting low birth weight at four central hospitals in vientiane, Lao PDR. Nagoya J Med Sci. 2010;72(1-2):51-8. 